\title{
ALTA TECNOLOGIA E REÚSO DE MATERIAIS DESCARTADOS: DESENVOLVIMENTO DE UM PAINEL DECORATIVO PARA A MELHORIA(DO DESEMPENHO TÉRMICO EM EDIFICAÇÕES
}

High technology and reuse of waste materials: developing a decorative panel for improvement of thermal performance

Maikol Yoshie Yabuki ${ }^{1}$, Caio Gomide Otoni ${ }^{1}$, Maria Gabriela Caffarena Celani ${ }^{1}$

RESUMO: O século XXI expressa um intenso avanço tecnológico aplicado nos mais diversos equipamentos gradualmente mais acessíveis à sociedade. Ao mesmo tempo, para atender a essa demanda, os recursos naturais são consumidos exponencialmente, gerando uma enorme quantidade de resíduos com destinação nem sempre adequada. Os principais agentes ligados à tentativa de redução desse impacto ambiental negativo por meio da reutilização de materiais são as cooperativas de reciclagem, responsáveis pela seleção dos materiais descartados e reintrodução no sistema produtivo. Através da Design Science Research, a pesquisa visa a criação de um artefato utilizando materiais descartados a fim de reintroduzi-los na cadeia produtiva sob a forma de elementos arquitetônicos de acabamento. Pela elevada representação nos materiais descartados, baixo índice de reaproveitamento e potencial de reconformação a quente, no estado fundido, o termoplástico poliestireno foi selecionado como matéria prima para o desenvolvimento de placas de acabamento para o teto (forro). Como maneira de agregar ainda mais valor ao produto, a constituição dos módulos do painel foi realizada a partir de moldes projetados com o uso de modelos paramétricos digitais e produzidos com o uso de impressora 3D. Além disso, o mesmo foi utilizado não apenas como acabamento estético, mas também como sistema de macroencapsulamento para um material de mudança de fase (phase change material), que contribui para o desempenho energético e o conforto térmico no ambiente em que é instalado. A pesquisa, de caráter interdisciplinar, envolveu pesquisadores das áreas de design, arquitetura, ciência dos materiais e conforto ambiental. O protótipo desenvolvido demonstra a possibilidade de se agregar valor a materiais descartados por meio de novas tecnologias de design, fabricação e materiais, e ainda contribui para a redução do gasto de energia, tanto na reciclagem do próprio plástico como na diminuição da temperatura do ambiente, apontando para possíveis desdobramentos de produção por cooperativas

PALAVRAS-CHAVE: Fabricação digital; Sistemas CAD/CAM; Sustentabilidade ambiental; Upcycling; Ornamento; Conforto térmico.

ABSTRACT: The 21st century expresses an intense technological advance applied in the most diverse equipment gradually more accessible to society. At the same time, to meet this demand, natural resources are consumed exponentially, generating a huge amount of waste with destination not always adequate. The main agents linked to the attempt to reduce this negative environmental impact through the reuse of materials are recycling cooperatives, responsible for the selection of discarded materials and reintroduction into the production system. Through Design Science Research, the research aims to create an artifact using waste materials to reintroduce them into the production chain as architectural finishing elements. Due to its high occurrence in the discarded materials, low reuse rate, and potential of being processed in the molten state, polystyrene was selected as a raw material for the development of ceiling finishing boards. As a way to add even more value to the product, the panel modules were constituted from molds designed using digital parametric models and produced using a 3D printer. In addition, it has not only been used as an aesthetic finish, but also as a macroencapsulation system for a phase change material, which contributes to energy performance and thermal comfort in the environment in which it is installed. The interdisciplinary research involved researchers from the areas of design, architecture, materials science, and environmental comfort. The developed prototype demonstrates the possibility of adding value to discarded materials through new technologies of design, manufacture, and materials science. It also contributes to the reduction of energy expenditure, both in the recycling of the plastic itself and in the reduction of the temperature of the material, pointing towards possible consequences of production by cooperatives.

KEYWORDS: Digital manufacturing; CAD/CAM systems; Sustainability; Upcycling; Ornament; Thermal comfort.

How to cite this article:

YABUKI, M. Y: OTONI, C. G.; CELANI, M. G. C. Alta tecnologia e reúso de materiais descartados desenvolvimento de um painel decorativo para a melhoria do desempenho térmico em edificações. Gestão e Tecnologia de Gestão e Tecnologia de

Fonte de Financiamento:

Conflito de Interesse:

Submetido em: Aceito em: 


\section{INTRODUÇÃO}

O século XXI expressa um acelerado processo de subsequentes avanços tecnológicos e aumento na disponibilidade de equipamentos que permitem incorporar essas inovações no mercado. Estas novas tecnologias provocam grandes alterações na sociedade de maneira geral, incluindo a arquitetura, onde não só alteram os modos como os projetos são desenvolvidos, mas também os processos de fabricação ou construção de elementos arquitetônicos e até mesmo de edificações completas.

Um dos resultados dessa difusão massiva de sistemas CAD/CAM (computer-aided design/computer-aided manufacturing) na arquitetura é a possibilidade de geração de texturas e padronagens com uma facilidade sem precedente. A partir do uso de computadores, geometrias complexas tornam-se possíveis e equipamentos com controle numérico computacional (CNC) como impressoras 3D, cortadoras a laser, fresadoras e tornos simplificam a fabricação de complicados elementos ornamentais, propiciando o retorno de seu uso na arquitetura contemporânea.

Outra característica da contemporaneidade é o progressivo aumento na quantidade de resíduos gerados pela população, resultado da intensa e desordenada utilização dos recursos naturais. Segundo o relatório publicado no ano de 2010 pelo Programa da Organização das Nações Unidas (ONU) para o Meio ambiente - PNUMA, cerca de 1,3 bilhão de toneladas de lixo são gerados por ano no mundo, com um crescimento previsto para 2,2 bilhões de toneladas em 2025. Por outro lado, vem surgindo uma intensificação da preocupação sobre a relação do homem com o meio ambiente e com sua sobrevivência no planeta Terra.

A busca pelo equilíbrio na relação da humanidade com o meio em que está inserida ao longo do tempo pode ser entendida como sustentabilidade ambiental, a qual envolve a habilidade de suprir suas necessidades atuais sem comprometer as gerações futuras de também suprirem as suas. Desta forma, um importante aspecto da sustentabilidade ambiental é a reutilização de materiais para conservação da matéria prima e energia empregada em sua produção, precedendo o sistema de reciclagem por evitar o reprocessamento, poupando gastos econômicos e energéticos, além de reduzir seu impacto ambiental.

Os principais agentes ligados a este processo são as cooperativas de reciclagem, que realizam a coleta seletiva dos materiais descartados e os inserem novamente no ciclo produtivo. Entre esses dois processos, há a oportunidade de intervenção dos próprios agentes de cooperativas sobre a reutilização dos resíduos sólidos urbanos com a possibilidade de gerar uma fonte alternativa de renda. Pelo empoderamento desses trabalhadores, pode-se tentar amenizar sua marginalização e coibir o estigma do reúso de materiais descartados.

Os produtos fabricados com materiais reutilizados ou reciclados são, em geral, artesanais, de baixa qualidade e frágeis. Dessa forma, existe a necessidade de incorporação de diversas funções e qualidades a esses artefatos para que a população se sinta atraída pela sua utilização. Com relação à arquitetura, dois importantes valores que podem ser agregados são a estética e o desempenho ambiental. Enquanto a utilização de phase change materials como sistema passivo de controle de temperaturas internas pode reduzir a energia gasta com o condicionamento artificial das edificações, a incorporação de qualidades estéticas torna os elementos arquitetônicos de acabamento mais agradáveis, agregando valor ao trabalho dos cooperados e possibilita uma fonte de renda alternativa.

\section{OBJETIVO}

Aproximando a sustentabilidade de um sistema completo de pensamento, envolvendo consciência, meio ambiente, economia e sociedade, esta 
pesquisa procura novas possibilidades de aplicação da alta tecnologia no conceito da economia circular. Dessa forma, busca desenvolver um artefato através da Design Science Research como metodologia de pesquisa utilizando sistemas CAD/CAM e equipamentos CNC em materiais plásticos descartados, a fim de reintroduzi-los na cadeia produtiva sob a forma de elementos arquitetônicos de acabamento. Sua produção visa aumentar a sustentabilidade no meio ambiente construído por meio do aumento da vida útil dos materiais empregados e auxiliar na redução do consumo de energia das edificações pelo controle passivo de temperaturas internas.

\section{FUNDAMENTAÇÃO TEÓRICA}

O levantamento de informações como base de conhecimento para o desenvolvimento deste trabalho configura a alta tecnologia dos sistemas CAD/ CAM e equipamentos CNC como tema central, orbitando em três grandes temas envolvidos: a reinterpretação do ornamento na arquitetura contemporânea, a sustentabilidade socioambiental, principalmente relacionada a resíduos sólidos urbanos, e o conforto térmico, por meio do controle passivo de temperaturas internas.

\section{SISTEMAS CAD/CAM E ARQUITETURA HIGH-LOW}

Nas últimas décadas, os avanços tecnológicos e o aumento da disponibilidade de equipamentos no mercado têm impactado o campo da arquitetura e da construção civil, abrindo novas oportunidades para a prática e para a produção arquitetônica. O Brasil já apresenta um significativo parque de equipamentos CNC. Desse modo, o custo e a disponibilidade dos equipamentos não podem mais ser considerados fatores limitantes para a incorporação dessas técnicas nos processos de projeto e construção de edificações (SILVA et al., 2009). Para Kolarevic (2003), essas tecnologias desafiam não só a prática projetual, mas também o modo como os edifícios estão sendo fabricados e construídos.

Consonante a essas iniciativas tecnológicas, surgiram, nos últimos anos, espaços abertos à comunidade equipados com ferramentas eletrônicas, softwares e equipamentos CNC; os Fab Labs (fabrication laboratories), vinculados à rede de laboratórios de fabricação digital do Massachusetts Institute of Technology (MIT), que se estende por mais de 100 países, com mais de 1.200 laboratórios pelo mundo, e os Makerspaces, com uma definição mais aberta de ambientes colaborativos para explorar e compartilhar o uso de ferramentas e equipamentos, inclusive computacionais e de alta tecnologia.

Segundo Save de Beaurecueil e Lee (2015), o conceito high-tech, ou alta tecnologia, em design, é definido como toda a geração de forma ou componente arquitetônico alcançada com o uso de ferramentas computacionais e com a fabricação digital, enquanto a low-tech, ou baixa tecnologia, caracteriza uma produção arquitetônica com base em processos locais manuais, não industrializados ou com uma tecnologia muito simples, e muitas vezes com o reúso de materiais. Dessa forma, os autores consideram que o conceito high-low tech na arquitetura estimula o reaproveitamento de materiais e componentes existentes na geração de formas arquitetônicas originais, além de servirem à fabricação digital de modelos e componentes construtivos propriamente ditos.

\section{O ORNAMENTO NA ARQUITETURA CONTEMPORÂNEA}

O uso de computadores torna possível a proposição de geometrias complexas e os equipamentos CNC simplificam a fabricação de complicados ele- 
mentos ornamentais, viabilizando o retorno de seu uso na arquitetura contemporânea de diversas maneiras. Segundo Jones (2001), o ornamento tem sido um elemento do projeto arquitetônico desde os tempos pré-históricos e seus conceitos de padrões decorativos foram regularmente inspirados pelas formas naturais e aplicados na arquitetura para mostrar o domínio do Homem sobre a natureza. O Estudo de Jones, publicado pela primeira vez em 1856, foi e continua sendo um dos principais inventários de arte ornamental ao longo da História e dos diversos povos que os desenvolveram.

No começo do século XX, devido ao processo de industrialização e sua influência nas mudanças culturais, o ornamento perdeu muito valor, principalmente na arquitetura. De acordo com Loveridge e Strehlke (2006), a ênfase do movimento moderno na forma sem adornos, combinada com o estabelecimento do international style e a substituição do trabalho à mão pela produção em massa, ocasionou uma sistemática eliminação do ornamento na arquitetura. Nesse contexto, o manifesto de Adolf Loos (2006), publicado pela primeira vez em 1913 com o título "Ornamento e Crime", marca uma mudança de paradigma com relação à aplicação de elementos decorativos, naquele momento considerados supérfluos, sobre as superfícies do edifício.

Ainda para Loveridge e Strehlke (2006), a redução do ornamento na arquitetura pode ser diretamente atribuída à intensificação do uso de máquinas nos processos de fabricação. Paradoxalmente, o retorno ao ornamento pode ser possível exatamente pelo uso de tecnologias CAD/CAM. Diferentes processos têm sido desenvolvidos para criar componentes usando diferentes tipos de fontes de informações e entrada de dados, mas, de qualquer modo, o método de trabalho foca sempre no ciclo completo de produção: da geração da geometria digital até a fabricação. A principal vantagem de usar sistemas $\mathrm{CAD} / \mathrm{CAM}$ é a possibilidade de gerar e fabricar inúmeras variações como resultado final.

Ao explorar esses novos limites e seguir o pensamento de Loveridge e Strehlke (2006) de que a customização em massa e a personalização na arquitetura podem atingir a grande escala, mas pode ser mais efetivo desenvolver inicialmente uma escala menor, esta pesquisa propõe a produção de elementos arquitetônicos de acabamento sem limitar-se a fatores estilísticos de ornamentos na arquitetura. Ao contrário da "falta de personalidade da arquitetura moderna", segundo Picon (2013), desenvolve-se o ornamento contemporâneo que este autor considera como uma aproximação altamente pessoal com o mundo, chegando a compará-lo com o uso de tatuagens e piercings, que, embora atualmente sejam uma característica das massas, objetivam afirmar a identidade e visão única de cada um.

\section{SUSTENTABILIDADE SOCIOAMBIENTAL}

O relatório elaborado pela Associação Brasileira das Empresas de Limpeza Pública e Resíduos Especiais - ABRELPE, em 2017, afirma que são coletadas 214,8 mil toneladas de resíduos sólidos por dia em 91,2\% do total de domicílios no país. Complementando a informação, a Pesquisa Nacional de Saneamento Básico realizada pelo Instituto Brasileiro de Geografia Estatística - IBGE, em 2008, indica que $31,9 \%$ do total de lixo gerado pela população é composto de material reciclável.

O potencial de reaproveitamento desses materiais não chega a ser explorado pelos $70,4 \%$ de municípios brasileiros que possuem alguma iniciativa de coleta seletiva, pois ainda há baixos índices de recuperação de materiais, como apenas $8,2 \%$ do plástico produzido pela indústria. Segundo relatório da ISWA - International Solid Waste Association, estima-se que entre 4,8 e 12,7 milhões de toneladas de resíduos de plástico foram lançados no meio marinho a partir de populações costeiras em 2010. Estima-se que mais 1,2 a 2,4 milhões de toneladas de plástico atingem os oceanos a cada ano a partir de fontes interiores através de rios. O impacto ambiental deste resíduo é enorme sobre a vida marinha, chegando às impressionantes imagens da quantidade de plástico retirada do estômago de aves ou tartarugas mortas. 
Figura 1: Processo de reciclagem, downcycling e upcycling

Fonte: elaborado pelos autores
Além do lançamento em meio marinho, os resíduos gerados pela população possuem diversos destinos possíveis, sendo os principais: aterros sanitários, incineração, reúso e reciclagem. Como tema de estudo, a reciclagem abrange três conceitos de acordo com as características finais do produto resultante: recycling, downcycling e upcycling. 0 termo reciclagem é mais comumente usado para se referir aos processos de recycling e downcycling; no primeiro caso, os materiais mantêm suas características físico-químicas depois de processados, enquanto no segundo caso, perdem qualidade após serem submetidos ao reprocessamento. McDonough e Braungart (2002) reafirmaram o termo usado pelo ambientalista e empresário alemão Reine Pilz, que utiliza upcycling para designar o objetivo de evitar o desperdício de materiais potencialmente úteis, reduzindo o consumo de novas matérias-primas e energia. Isto torna a prática ainda mais positiva, do ponto de vista ecológico, do que a própria reciclagem.

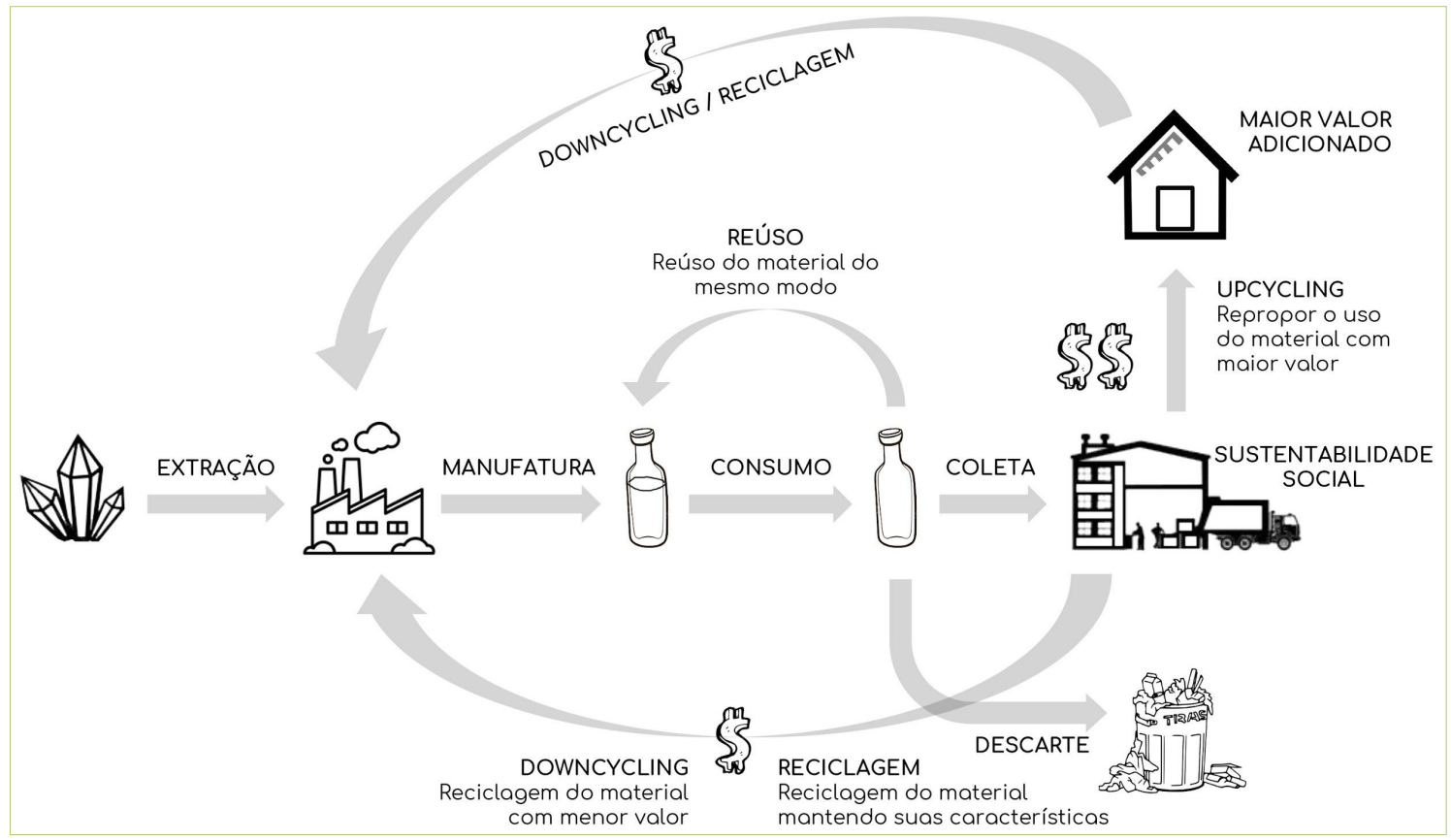

De acordo com relatório do Instituto de Pesquisa Econômica Aplicada - Ipea (2010), os principais agentes ligados ao processo de reciclagem são, de maneira geral, pessoas inseridas em jornadas informais de trabalho, com baixa escolaridade, e que convivem em um ambiente de múltiplas precariedades, dificultando a consolidação de um empreendimento cooperativo. As organizações que conseguem ultrapassar estas barreiras iniciais para a formação do empreendimento, muitas vezes com o apoio técnico e financeiro de entidades de fomento ou poder público, tendem a inserir-se de maneira mais vantajosa na cadeia de valor da reciclagem.

Dessa forma, os objetivos desta pesquisa se concentram em estabelecer meios para o beneficiamento de materiais descartados para além da possibilidade de gerar uma fonte alternativa de renda a esses trabalhadores, capacitando-os em novas tecnologias, aumentando sua consciência ambiental e estabelecendo um meio de reconhecimento, valorização social e redução da marginalização dessa população.

\section{DESEMPENHO TÉRMICO EM EDIFICAÇÕES}

Segundo Borges (2008), o conceito de desempenho na construção civil está, há muitos anos, associado ao comportamento no uso de edificações, dentro de determinadas condições. $\mathrm{O}$ edifício é um produto que deve apresentar determinadas 
características que o capacite a cumprir objetivos e funções para os quais foi projetado, quando submetido a determinadas condições de exposição e uso. Assim, ele é considerado "bem-comportado" quando atende aos requisitos para o qual foi projetado. Ainda para o autor, do ponto de vista técnico, o conceito de desempenho não se aplica apenas a sistemas, mas também a elementos e componentes. $\mathrm{O}$ edifício é percebido como um grande sistema constituído de sistemas, elementos e componentes que interagem entre si, cada um com uma função determinada para a obtenção do desempenho global e de cada parte.

A partir da utilização de aparelhos mecânicos e elétricos para condicionar artificialmente os espaços por meio de aquecimento, arrefecimento, ventilação e iluminação, o entorno dos edifícios deixou de ser o principal moderador dos ambientes internos e os projetistas reduziram sua responsabilidade sobre a climatização natural e eficiência energética. Com a atual e crescente preocupação ambiental, há uma busca por alternativas que solucionem essa dependência por meio de estratégias passivas de climatização que reduzam o consumo energético na oferta de conforto térmico aos usuários.

Para Gonçalves e Graça (2004), os sistemas passivos se referem a dispositivos construtivos integrados nos edifícios, cujo objetivo é o de contribuir para o seu aquecimento ou arrefecimento natural. Os autores consideram que a massa térmica desempenha um papel estabilizador das condições interiores, atenuando a amplitude térmica dos edifícios. Quanto maior for a massa térmica, menor será essa variação, sendo que também será mais difícil aquecer (nos climas quentes) ou resfriar (nos climas frios) o edifício, sendo necessário um equilibrio entre massa térmica, isolamento e área de vãos, dependendo muito do tipo de edifício e localização do mesmo. Nos climas quentes, durante o período diurno, a massa térmica absorve o calor resultante da incidência direta da radiação solar e, durante o período noturno, devolve-o ao espaço.

Um dos dispositivos que podem ser integrados ao edifício para aumentar a massa térmica de elementos construtivos são os materiais de mudança de fase, mais conhecidos por seu nome em inglês, phase change materials - PCMs. Esta tecnologia promissora, que recebeu atenção considerável ao longo da última década, utiliza o princípio de armazenamento térmico por calor latente ou latent heat thermal storage (LHTS) para absorver energia em grandes quantidades quando há um excedente e liberá-la quando há um déficit. Para Kalnaes e Jelle (2015), o uso correto de PCMs pode reduzir o pico de aquecimento e reduzir o uso de energia gasto em equipamentos técnicos para aquecimento e resfriamento. Um benefício adicional é sua capacidade de manter o ambiente interno mais confortável devido a menores flutuações de temperatura.

Os PCMs utilizam o calor latente da mudança de fase para controlar as temperaturas dentro de uma faixa específica. Quando a temperatura sobe acima de um certo ponto, o material atravessa o processo endotérmico de fusão, com a consequente absorção de altas quantidades de energia. No processo inverso, mediante redução da temperatura, o material solidifica-se, liberando também altas quantidades de calor. A energia usada na transição física do PCM, sendo suas temperaturas de fusão e cristalização podem ser ajustadas para próximas à temperatura ambiente desejada, levará a um clima interno mais estável e confortável, além de reduzir as cargas de resfriamento e aquecimento (Baetens et al., 2010).

\section{MATERIAIS E MÉTODOS}

Segundo Goldratt (1986), “[...] o conhecimento que nos rodeia não é um objetivo a ser alcançado por si só. Ele deve ser perseguido, acredito, para tornar o nosso mundo um lugar melhor e a vida mais gratificante [...]”. No sentido contrário dessa ideia, Dresch et al. (2015) apresentam o levantamento da revista The Economist de agosto de 2007, que revela que os periódicos acadêmicos publicam mais de 20.000 artigos por ano. A maior parte da pesquisa é altamente quantitativa, orientada a hipóteses e esotérica. Segundo os autores, como resultado disso, é quase que universalmente não lida pelos gestores do mundo real.

A necessidade de ser relevante para os profissionais não dispensa a pesquisa da necessidade de ser reconhecida pela comunidade acadêmica, garantindo, 
assim, o avanço do conhecimento, segundo Daft e Lewin (2008). O rigor é outro predicado que deve estar presente desde a sua condução até a apresentação dos resultados (VAN AKEN, 2005; HATCHUEL, 2009). A maior precisão metodológica auxilia a assegurar a validade da pesquisa e o reconhecimento com boa condução e confiabilidade.

Um possível esclarecimento para a distância encontrada entre o meio acadêmico (teoria) e organizações (prática) pode ser encontrado nos métodos utilizados para o desenvolvimento de pesquisas em ciências naturais e artificiais. Apesar de ambas serem consideradas ciências baseadas em fatos empíricos, elas são essencialmente diferentes. Segundo Simon (1996), a ciência natural se refere a um conjunto de conhecimentos sobre uma classe de objetos e/ou fenômenos (características, comportamentos e interações). Nesse sentido, é tarefa das disciplinas científicas naturais pesquisarem e ensinarem como as coisas são e como elas funcionam. No entanto, para Dresch et al. (2015), não basta compreender profundamente um fenômeno (o fenômeno em si, seus antecedentes, suas consequências, seus mediadores). Precisamos desenvolver conhecimentos sobre como intervir em determinada situação e gerar os resultados desejados.

Dessa forma, Simon (1996) levanta a possibilidade de estudos sobre o universo artificial, definindo que as ciências do artificial se ocupam da concepção de artefatos que realizem objetivos. $\mathrm{O}$ autor salienta a necessidade de criar uma ciência (i.e., um corpo de conhecimento rigoroso e validado) que se dedique à proposição de artefatos com propriedades desejadas, ou seja, uma ciência de projeto ou Design Science. A missão principal da Design Science é, portanto, desenvolver conhecimento para a concepção e desenvolvimento de artefatos (VAN AKEN, 2004).

No que diz respeito aos métodos de pesquisa, podemos conceituá-los como um conjunto de passos reconhecidos pela comunidade acadêmica e utilizados pelos pesquisadores para a construção do conhecimento científico (ANDERY et al., 2004). Dessa forma, a Design Science Research é um método que fundamenta e operacionaliza a condução da pesquisa quando o objetivo a ser alcançado é um artefato ou uma prescrição. Como método de pesquisa orientado à solução de problemas, a Design Science Research busca, a partir do entendimento do problema, construir e avaliar artefatos que permitam transformar situações, alterando suas condições para estados melhores ou desejáveis (DRESCH et al., 2015).

Considerando a condução da metodologia Design Science Research de diversos autores, esta pesquisa segue o método proposto por Dresch et al. (2015).

\section{IDENTIFICAÇÃO DO PROBLEMA}

A alta tecnologia de sistemas CAD/CAM e equipamentos CNC tem seu desenvolvimento voltado principalmente para a criação de novos sistemas e produtos com um nível de consciência modesto a respeito da procedência de sua matéria prima ou da destinação final com o término de sua vida útil. A partir da grande quantidade de resíduos sólidos gerada por dia no Brasil e do grande potencial para sua reintrodução no ciclo produtivo, verifica-se uma possibilidade de pensar a sustentabilidade como um sistema completo de pensamento.

Dessa forma, a questão de pesquisa se formaliza em torno das possibilidades de aplicação de alta tecnologia na reintrodução de materiais descartados na cadeira produtiva, incorporando aspectos estéticos e de conforto térmico para o desenvolvimento de um elemento arquitetônico de acabamento.

\section{CONSCIENTIZAÇÃO DO PROBLEMA}

Além das informações levantadas na fundamentação teórica, também há necessidade de considerar as dificuldades limitantes para o desenvolvimento do artefato em cada um dos temas envolvidos na pesquisa. 
Com relação aos avanços tecnológicos, há necessidade de desenvolver uma solução de baixa complexidade para capacitação, principalmente, de agentes ligados às cooperativas de reciclagem. Apesar da grande quantidade de resíduos plásticos coletados no Brasil, é preciso investigar quais tipos do material podem ser submetidos a sistemas CAD/CAM. As questões estéticas envolvem diversos fatores culturais. Dessa forma, o desenvolvimento do elemento arquitetônico de acabamento deve ser adaptável a diferentes estilos e personalizações para maior aceitação no mercado. A incorporação de PCM deve considerar uma solução alternativa de baixo custo frente ao elevado valor dos produtos encontrados no mercado que utilizam esses materiais, e que seja proveniente, preferencialmente, de fontes renováveis.

Além das características levantadas acima, o elemento arquitetônico de acabamento a ser desenvolvido deve considerar características como funcionalidade, durabilidade, estabilidade, estanqueidade e atendimento às normas brasileiras, principalmente de resistência ao fogo.

\section{IDENTIFICAÇÃO DOS ARTEFATOS COMO SOLUÇÃO}

A pesquisa buscou iniciativas de aplicação de alta tecnologia em materiais descartados que possam relacionar-se com o desenvolvimento do artefato. A partir da busca por referências projetuais, o quadro abaixo apresenta os principais resultados e suas características conceituais e práticas.

Figura 2: Iniciativas de aplicação de alta tecnologia em materiais descartados

Fonte: elaborado pelos autores.

\begin{tabular}{|c|c|c|c|c|c|c|c|c|}
\hline PROPOSTA & AUTORES & ANO & LOCAL & TIPOLOGIA & $\begin{array}{l}\text { LIGAÇÃO } \\
\text { ACADÊMICA }\end{array}$ & $\begin{array}{c}\text { MATERIAIS } \\
\text { REUTILIZADOS }\end{array}$ & $\begin{array}{l}\text { FERRAMENTAS } \\
\text { CAD UTILIZADAS } \\
\text { PARA DESIGN }\end{array}$ & $\begin{array}{c}\text { FERRAMENTAS } \\
\text { CAM UTILIZADAS } \\
\text { PARA } \\
\text { FABRICAÇÄO }\end{array}$ \\
\hline JUNK & $\begin{array}{l}\text { Alunos do } \\
\text { Georgia } \\
\text { Institute of } \\
\text { Technology }\end{array}$ & 2011 & Atlanta - USA & $\begin{array}{l}\text { Arquitetura } \\
\text { efêmera }\end{array}$ & $\begin{array}{c}\text { Georgia Institute } \\
\text { of Technology }\end{array}$ & $\begin{array}{c}\text { Garrafas plásticas } \\
\text { de refrigerante / } \\
\text { elásticos / anéis de } \\
\text { acrílico }\end{array}$ & $\begin{array}{c}\text { Modelagem } \\
\text { tridimensional / } \\
\text { desenho } \\
\text { bidimensional }\end{array}$ & $\begin{array}{l}\text { CNC - fresadora } \\
\text { para corte dos anéis } \\
\text { de acrílico }\end{array}$ \\
\hline $\begin{array}{l}\text { RECYCLED TOY } \\
\text { FURNITURE }\end{array}$ & Greg Lynn & 2008 & $\begin{array}{c}\text { Los Angeles - USA } \\
\text { para Bienal de } \\
\text { Veneza }\end{array}$ & $\begin{array}{l}\text { Mobiliário / } \\
\text { instalação } \\
\text { artística }\end{array}$ & --- & $\begin{array}{l}\text { Brinquedos infantis } \\
\text { plásticos }\end{array}$ & $\begin{array}{l}\text { Digitalização 3D por } \\
\text { laser / Modelagem } \\
\text { tridimensional }\end{array}$ & $\begin{array}{c}\text { Braço robótico de } 6 \\
\text { eixos para cortar } \\
\text { peças }\end{array}$ \\
\hline JUGAAD & $\begin{array}{l}\text { Sanjeev } \\
\text { Shankar }\end{array}$ & 2008 & Nova Delhi - Índia & $\begin{array}{l}\text { Arquitetura } \\
\text { efêmera }\end{array}$ & $\begin{array}{c}\text { Goethe Institute } \\
\text { / German } \\
\text { Technical } \\
\text { Cooperation } \\
\text { (GTZ) }\end{array}$ & $\begin{array}{l}\text { Latas de óleo } \\
\text { metálicas }\end{array}$ & $\begin{array}{l}\text { Modelagem } \\
\text { tridimensional }\end{array}$ & - \\
\hline $\begin{array}{l}\text { REPURPOSED } \\
\text { POLITICAL PLY }\end{array}$ & $\begin{array}{l}\text { Jason Griffiths I } \\
\text { alunos da } \\
\text { Arizona State } \\
\text { University }\end{array}$ & 2009 & Tempe - USA & $\begin{array}{l}\text { Arquitetura } \\
\text { efêmera }\end{array}$ & $\begin{array}{c}\text { Arizona State } \\
\text { University }\end{array}$ & $\begin{array}{l}\text { Posteres de } \\
\text { campanhas } \\
\text { políticas }\end{array}$ & $\begin{array}{c}\text { Modelagem } \\
\text { tridimensional / } \\
\text { planificação de } \\
\text { volumes } \\
\text { (Rhinoceros) }\end{array}$ & $\begin{array}{l}\text { CNC - fresadora } \\
\text { para corte e frisos } \\
\text { de dobras nos } \\
\text { painéis }\end{array}$ \\
\hline PLAYSCAPE & $\begin{array}{c}\text { Cameron } \\
\text { Acheson / Bill } \\
\text { Batey / } \\
\text { Courtney } \\
\text { Mathias / Jamie }\end{array}$ & 2010 & Alabama - USA & $\begin{array}{l}\text { Arquitetura } \\
\text { efêmera }\end{array}$ & $\begin{array}{l}\text { Auburn } \\
\text { University }\end{array}$ & $\begin{array}{c}\text { Galões } \\
\text { galvanizados }\end{array}$ & $\begin{array}{c}\text { Modelagem } \\
\text { tridimensional / } \\
\text { desenho } \\
\text { bidimensional }\end{array}$ & - \\
\hline $\begin{array}{l}\text { WATER BRANCH } \\
\text { HOUSE }\end{array}$ & Kengo Kuma & 2008 & New York - USA & $\begin{array}{l}\text { Arquitetura } \\
\text { efêmera }\end{array}$ & -- & Tanques plásticos & $\begin{array}{c}\text { Modelagem } \\
\text { tridimensional / } \\
\text { desenho } \\
\text { bidimensional }\end{array}$ & - \\
\hline $\begin{array}{l}\text { GRINDSHELL } \\
\text { STRUCTURE }\end{array}$ & $\begin{array}{l}\text { Ayodh Vasant } \\
\text { Kamath }\end{array}$ & 2015 & $\begin{array}{c}\text { Pennsylvania - } \\
\text { USA }\end{array}$ & $\begin{array}{l}\text { Arquitetura } \\
\text { efêmera }\end{array}$ & $\begin{array}{l}\text { University of } \\
\text { Pennsylvania }\end{array}$ & $\begin{array}{l}\text { Tapumes de } \\
\text { madeira } \\
\text { recuperados }\end{array}$ & $\begin{array}{c}\text { Modelagem } \\
\text { tridimensional / } \\
\text { Scripts Rhinoceros }\end{array}$ & $\begin{array}{l}\text { CNC - fresadora } \\
\text { para corte das } \\
\text { peças de madeira }\end{array}$ \\
\hline $\begin{array}{c}\text { PERPETUAL PLASTIC } \\
\text { PROJECT }\end{array}$ & $\begin{array}{l}\text { Better Future } \\
\text { Factory }\end{array}$ & 2012 & $\begin{array}{l}\text { Rotterdam - } \\
\text { Holanda }\end{array}$ & $\begin{array}{c}\text { Filamento } \\
\text { impressoras 3D }\end{array}$ & -- & $\begin{array}{l}\text { Plástico } \\
\text { descartável }\end{array}$ & $\begin{array}{l}\text { Repositórios de } \\
\text { modelos 3D para } \\
\text { impressão }\end{array}$ & Impressora 3D \\
\hline
\end{tabular}

De acordo com as referências projetuais identificadas, pode-se verificar que boa parte dos processos criativos são destinados a arquiteturas efêmeras ou instalações artísticas. Assim, questões como estabilidade (dos materiais empregados) e durabilidade não são consideradas como fatores essenciais em seu desenvolvimento. A maioria das iniciativas possui relação com o meio acadêmico, demonstrando um interesse de pesquisa, mas que não necessariamente 
alcançam o mercado produtivo. Grande parte dos exemplos são recentes, dos últimos dez anos, o que pode ser a causa dessa ausência de ligação com o mercado. Os materiais empregados são bastante diversos e quase todos os projetos utilizam sistemas CAD na fase de projeto. Contudo, a produção não acompanha essa tendência; a manufatura assistida por computador não é empregada ou utilizada apenas em etapas ou partes do design, o que mostra uma dificuldade na conciliação dos materiais descartados com equipamentos CNC.

\section{PROPOSIÇÃO DOS ARTEFATOS}

A fase prática da pesquisa foi iniciada com visitas às duas cooperativas de reciclagem na cidade de Rio Claro - SP: Cooperviva e Novo Tempo. Ambas organizações possuem apoio da Prefeitura Municipal para organização e regularização dos espaços ocupados e coleta seletiva do município. Os materiais coletados seguem a tendência apresentada no panorama de resíduos sólidos apresentado pela ABRELPE com destaque para embalagens plásticas, papel/papelão e metais (em menor quantidade). Os plásticos mais recorrentes neste ambiente foram coletados para a pesquisa: polietileno de alta densidade (PEAD), polipropileno (PP), poli(tereftalato de etileno) (PET) e poliestireno (PS).

Os principais meios de transformação aos quais estes materiais podem ser submetidos foram investigados através de visitas a diversos maker spaces e laboratórios de fabricação digital. Dentre os aparelhos disponíveis, destaca-se a termoformadora a vácuo, por ser um dispositivo que exige um menor nível de conhecimento técnico para operação, baixo custo e indicação para o trabalho com materiais termoplásticos. Apesar deste não ser um equipamento de controle numérico, ele é comumente utilizado em conjunto com moldes produzidos por equipamentos de fabricação digital. A tecnologia da moldagem por termoformação a vácuo consiste no aquecimento de uma prancha plástica até que ela sofra amolecimento e, a partir daí, seja forçada contra um molde por meio de pressão negativa.

Os moldes a serem utilizados no equipamento podem ser desenhados parametricamente por sistemas CAD (3DS Max, Rhinoceros, Grasshopper) para atender a diferentes estilos ou preferências dos usuários, e produzidos por equipamentos CNC como impressoras 3D ou fresadoras. Dessa forma, o processo de produção consegue envolver diversas frentes de trabalho em sistemas CAD/ CAM.

Após a definição do material e meio de transformação, foram realizados diversos testes com os tipos de plásticos coletados para verificar qual deles apresenta melhor resposta à termomoldagem a vácuo. Pela boa estabilidade depois de aquecido, boa transferência da forma do molde para o material e baixo tempo de aquecimento, o PS foi o polímero com maior potencial para o desenvolvimento do artefato.

A termomoldagem a vácuo permite a configuração de pequenos módulos que podem compor placas de maiores dimensões pela justaposição destas peças em diferentes combinações. Dessa forma, verificou-se a possibilidade de usar telas aramadas para suporte dos elementos e, assim, configurá-los como placas de forro ou painéis decorativos internos. Contudo, em uma possível aplicação na vertical, seria difícil garantir a estanqueidade do material líquido dentro das cápsulas.

A partir da proposição do material que conterá o PCM e de suporte para os módulos, também foram avaliadas as possibilidades de utilização de diferentes materiais como PCM em substituição às opções existentes no mercado com custo elevado. Para isso, participaram como parceiros desta pesquisa o Prof. Dr. Watson Loh e o Dr. Caio Otoni, do Instituto de Química da UNICAMP; a Profa. Dra. Sabine Hoffmann, do Departament of Built Environment da Technische Universitat Kaiserslautern (Alemanha); e a Profa. Dra. Lucila Labaki, do Departamento de Conforto Ambiental e Física Aplicada da UNICAMP.

A seleção do PCM iniciou-se pelo levantamento das informações climáticas da cidade de Campinas - SP para definir as características necessárias a seu me- 
lhor funcionamento. Dessa forma, definiu-se que o PCM deveria ter uma temperatura de mudança de estado em torno dos $28^{\circ} \mathrm{C}$. A primeira opção foi uma parafina específica para este ponto de fusão/solidificação. Apesar de possuírem baixa toxicidade, as parafinas merecem atenção em função da carga de fogo em caso de incêndio, além de serem obtidas majoritariamente de fontes naturais não renováveis.

Um material orgânico, comumente usado no Brasil para outros fins, chamou atenção por ter um ponto de fusão bastante próximo do necessário, entre 26 e $28^{\circ} \mathrm{C}$ : o óleo de coco. Também chamado de azeite ou manteiga de coco, é um óleo vegetal composto por aproximadamente $90 \%$ de ácidos graxos extraídos pela prensagem da polpa do fruto. Embora essa aplicação seja praticamente desconhecida no Brasil, o potencial do óleo de coco como PCM tem sido amplamente explorado para o armazenamento de energia térmica (calor latente) em edifícios, segundo Saleel et al. (2018). Para o mesmo autor, as características que comprovam seu potencial são as propriedades termofísicas com uma mudança de fase dentro da variação de temperatura de conforto $\left(24-27^{\circ} \mathrm{C}\right)$, baixo custo pela oferta abundante do material, estabilidade em temperaturas altas pelo seu alto ponto de fumaça (temperatura a qual, sob determinadas condições, o material começa a produzir uma fumaça claramente visível), alto ponto de ebulição, segurança, baixa reatividade, e rápida cristalização.

Também foram verificados os elementos presentes no mercado que utilizam PCM como meio passivo de controle térmico. Verifica-se uma grande quantidade de materiais que começaram a incorporar PCM em suas composições. Apesar disso, o preço elevado dos produtos finais ocasiona uma baixa utilização no mercado. Também foram investigados revestimentos decorativos para paredes e tetos em relevo, produzidos em PS, disponíveis no mercado. Verificou-se a existência de painéis de revestimento 3D fabricados por modelagem bidimensional, tridimensional e termomoldados a vácuo.

Esses produtos são fabricados no modelo da economia linear e vendidos em grandes lojas de materiais de acabamento e comércio eletrônico. A produção de um artefato personalizado, fabricado com materiais alternativos que possam oferecer uma solução mais sustentável em todos os seus aspectos, parece, portanto, ser bastante inovadora e com bom potencial de sucesso.

\section{PROJETO DO ARTEFATO}

A partir das proposições levantadas na etapa anterior, o projeto do artefato define os principais meios que serão considerados em cada um dos temas envolvidos para o desenvolvimento da pesquisa.

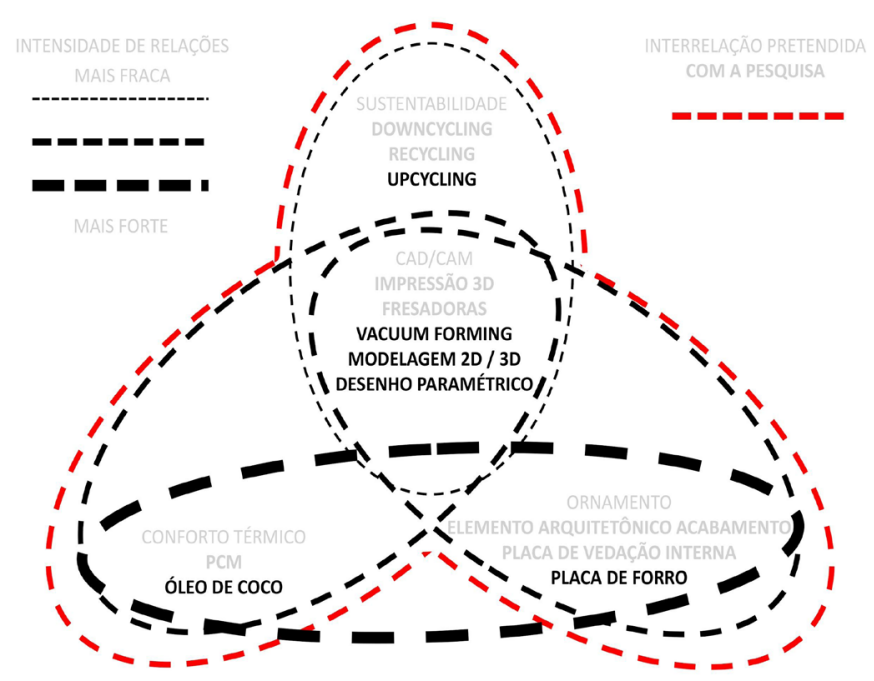

Figura 3: Infográfico de interrelação entre temas da pesquisa

Fonte: elaborado pelos autores 
A Figura 3 evidencia que a relação mais forte é entre os elementos arquitetônicos de acabamento e o PCM, pela grande quantidade de produtos já encontrados no mercado. A relação entre os elementos arquitetônicos de acabamento com sistemas CAD/CAM já apresenta produtos no mercado como os revestimentos 3D fabricados em larga escala industrial através de termomoldagem, mas trata-se de uma solução cuja forma de produção não possui valor agregado. Por meio de trabalhos acadêmicos, pode-se perceber que a utilização de vacuum forming para contenção de PCM em painéis já foi estudada de maneira embrionária. A relação mais fraca encontrada, que receberá maior atenção no desenvolvimento deste projeto, é o upcycling de materiais descartados utilizando sistemas CAD/CAM. Apesar de já serem encontradas iniciativas nesse sentido, o foco é voltado principalmente para arquiteturas efêmeras e instalações artísticas, sem fins comerciais na arquitetura.

Outras informações que podem ser verificadas no infográfico são os destaques com letras em negrito sobre as definições do que serão considerados dentro de cada um dos temas. O UPCYCLING de materiais descartados utilizando DESENHO PARAMÉTRICO para MODELAGEM 2D / 3D e produção em VACUUM FORMING de PLACAS DE FORRO incorporando ÓLEO DE COCO como phase change material.

\section{DESENVOLVIMENTO DO ARTEFATO}

A partir das definições de projeto, pode-se elaborar uma sequência de atividades para o desenvolvimento do artefato desde a matéria prima até sua produção final.

Inicialmente ocorre a coleta de material descartado. Pelos resultados positivos com o PS, o material foi selecionado para dar prosseguimento à pesquisa, mas a reduzida espessura da maioria dos objetos em PS encontrados entre os materiais para reciclagem é um fator a ser analisado com maior atenção pois, apesar de favorecer as trocas térmicas, essa espessura reduzida pode comprometer a durabilidade do artefato. O processo tem continuidade com a limpeza dos objetos coletados e posterior planificação por meio de cortes.

Concomitantemente, há algumas atividades relativas ao desenvolvimento do molde para a termomoldagem. Sua modelagem é realizada por desenho paramétrico utilizando algoritmos computacionais (Grasshopper), possibilitando sua adaptação a diferentes usuários e características. Os parâmetros a serem considerados no algoritmo computacional relacionam-se às dimensões e formato da base para se adaptar a diferentes telas aramadas comerciais, quantidade e formato das aletas a serem instaladas no módulo, e altura das aletas para controle do volume de PCM em seu interior.

Após o projeto do molde, por meio de parâmetros, gera-se uma instanciação do modelo a ser produzido com as características selecionadas. Com auxílio computacional de impressoras 3D ou fresadoras CNC, os moldes são produzidos.

Voltando ao fluxo principal de desenvolvimento, com o material plástico limpo, planificado e o molde gerado, moldam-se as cápsulas que conterão PCM por meio da termomoldagem a vácuo. As cápsulas modulares são armazenadas e, posteriormente, encaixadas em uma base de tela aramada.

O óleo de coco a ser colocado nos módulos é aquecido acima de sua temperatura de fusão para facilitar o preenchimento. Com as cápsulas preenchidas, o painel é selado com uma prancha plana composta por adesivo plástico. Assim, o produto encontra-se pronto para instalação na forma de painéis que podem ser atirantados à laje ou estrutura do telhado, por meio de suportes presos na tela aramada do artefato. Em caso de posterior desuso do painel, ele poderá ser descartado com a separação de seus materiais compo- 
nentes, que serão encaminhados novamente às cooperativas de reciclagem.

Durante o desenvolvimento do artefato foram produzidos protótipos para verificação de resultados preliminares. Um modelo do molde foi desenvolvido em 3DS Max considerando aletas verticais inclinadas para aumentar a superfície de contato do módulo com o ar ambiente e seu desenho foi pensado de maneira a possibilitar uma composição com os demais módulos laterais. As dimensões foram baseadas no maior espaçamento encontrado em telas aramadas comerciais: vãos quadrados com $5 \mathrm{~cm}$ de aresta. 0 dimensionamento é compatível com os materiais de pequenas dimensões (copos e pratos descartáveis) usualmente encontrados em cooperativas de reciclagem.

Os módulos são encaixados nos vãos da tela aramada de padrão comercial para a composição do painel a ser preenchido com óleo de coco e, posteriormente, submetido a testes de comportamento ambiental.

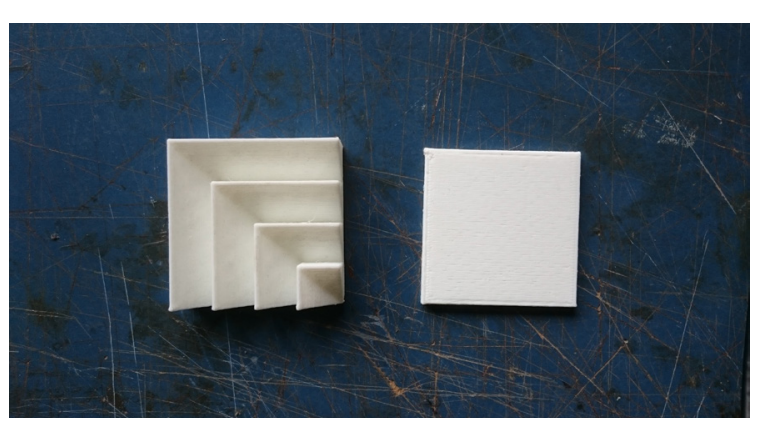

Figura 4: Molde fabricado em impressora 3D

Fonte: elaborado pelos autores

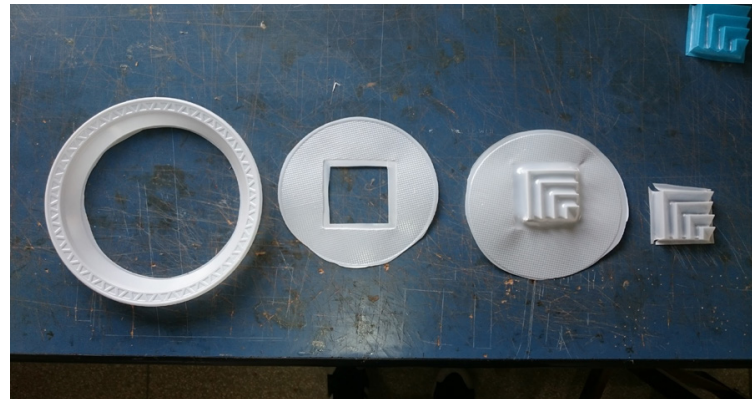

Figura 5: Processo de planificação por corte e resultado da termomoldagem

Fonte: elaborado pelos autores

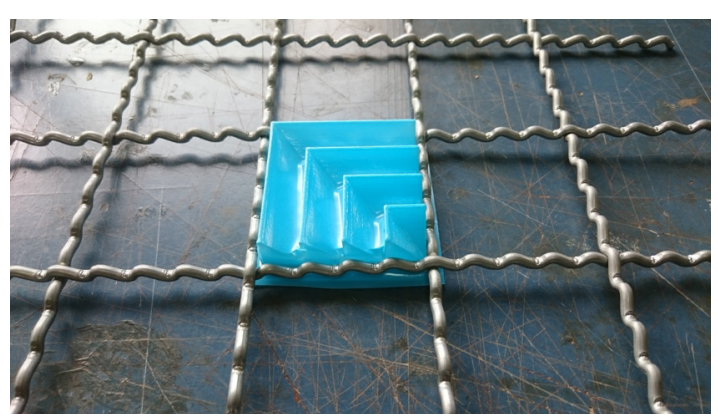

Figura 6: Encaixe do módulo na tela aramada de suporte Fonte: elaborado pelos autores

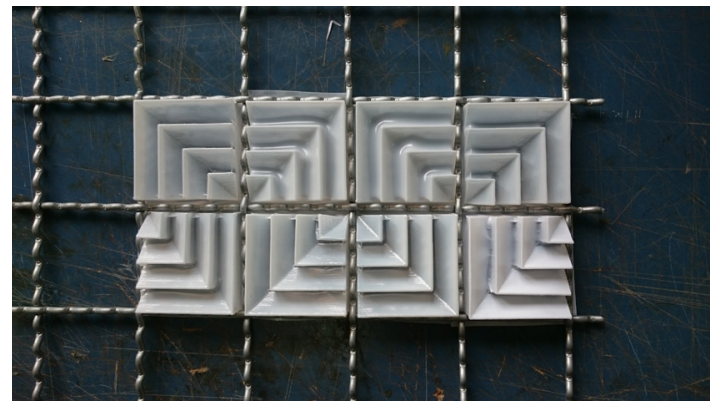

Figura 7: Composição dos

módulos na tela de suporte

Fonte: elaborado pelos autores

\section{AVALIAÇÃO DO ARTEFATO}

Os modelos produzidos são testados de duas maneiras: por simulação computacional e por testes físicos. As simulações computacionais são realizadas em plugins de avaliação de comportamento térmico, no Grasshopper. Para o teste físico, duas câmaras foram produzidas em MDF, como simulações de ambientes reais. As caixas são produzidas em compensado de madeira com $5 \mathrm{~mm}$ de espessura, acabamento na cor branca e dimensões de $0,625 \times 0,560 \times 0,600 \mathrm{~m}^{3}$. Os fundos das caixas, que não são expostos ao sol, possuem espessura de $15 \mathrm{~mm}$ e foram pintados na cor preta. Também existem aberturas de 120x120 mm² nas laterais de menor dimensão com a instalação de ventiladores em um dos lados, e de uma tela no outro para simulação de corrente de ar constante pelo ambiente. O painel de PCM desenvolvido foi fixado na tampa de uma das câmaras com uma distância de $50 \mathrm{~mm}$ da mesma, enquanto a outra, sem nenhum dispositivo de controle ambiental que possa interferir em suas condições climáticas, serve de controle. 
Figura 8: Corte esquemático da câmara de testes físicos com o painel

Fonte: Elaborado pelos autores

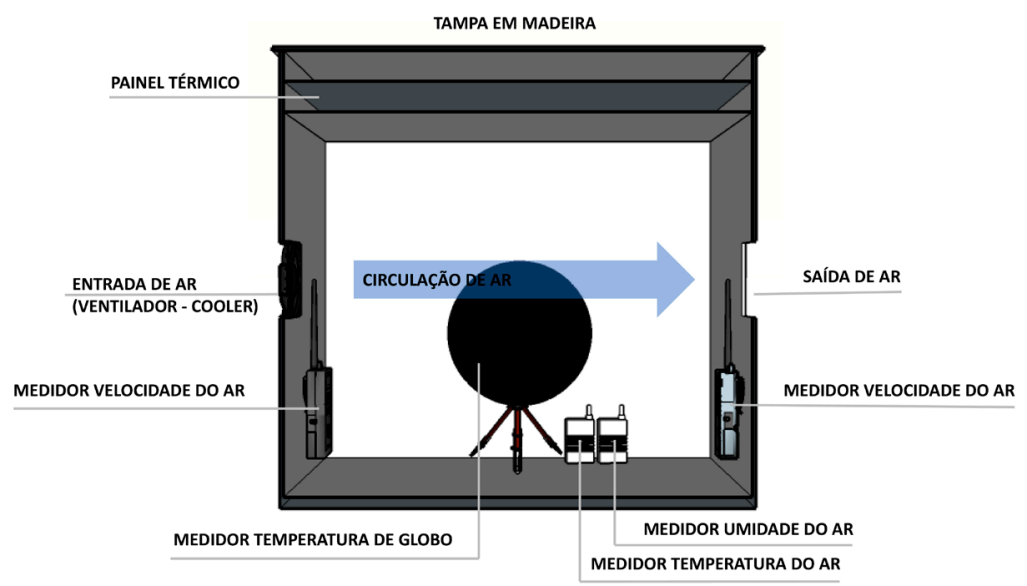

Por possuírem pequenas dimensões, os módulos do painel não foram escalados na mesma proporção da maquete. Dessa forma, os resultados encontrados não serão proporcionais às condições reais diretamente, mas deverão passar por correções de cálculo para consideração.

\section{CONCLUSÕES}

Conceituando a sustentabilidade como um sistema abrangente de pensamento, a pesquisa multidisciplinar buscou conhecimento para capacitar os agentes de cooperativas de reciclagem na incorporação de alta tecnologia com aspectos estéticos e de conforto ambiental em materiais descartados que passam desvalorizados cotidianamente em suas mãos.

Dessa maneira, foram levantados os principais materiais descartados e coletados que possam passar por um processo de reintrodução na cadeia produtiva que envolva sistemas CAD/CAM de baixa complexidade para que pessoas com pouco conhecimento técnico consigam executá-lo. A etapa de programação para o desenho paramétrico, como a fase menos acessível no desenvolvimento do artefato, apresenta, como resultado, uma interface simples objetivando apenas a geração de moldes a serem utilizados na termomoldagem a vácuo. Assim, a utilização de materiais comuns descartados, equipamentos CNC menos complexos e elementos construtivos complementares já existentes no mercado podem aproximar o artefato criado das pessoas interessadas.

O desenvolvimento da pesquisa nas etapas descritas pela metodologia de Design Science Research pode contribuir para a disseminação de sua utilização na criação de artefatos e por meio da reintrodução de resíduos sólidos na cadeia produtiva, busca-se ampliar as possibilidades de utilização de ferramentas $\mathrm{CAD} / \mathrm{CAM}$ nos campos do design, da arquitetura e da construção civil.

\section{REFERÊNCIAS}

ABRELPE - Associação Brasileira de empresas de limpeza pública e resíduos especiais. Panorama dos resíduos sólidos no Brasil. São Paulo: ABRELPE, 2017. Disponível em: <http://abrelpe.org.br/panorama>. Acesso em 25 de out. de 2017.

ANDERY, M. A. et al. Para compreen- der a ciência: uma perspectiva histórica. Rio de Janeiro: EDUC, 2004

BAETENS, R.; JELLE, B. P.; GUSTAVSEN, A. Phase change materials for buiIding applications: A state-of-the-art review. Energy and Buildings, v. 42, n. 9, p. 1361-1368, 2010. 
DAFT, R. L.; LEWIN, A. Y. Rigor and relevance in organization studies: idea migration and academic journal evolution. Organization Science, v. 19, n. 1, p. 177-183, 2008

DRESCH, A.; LACERDA, D. P.; ANTUNES, J.A.V. Design Science research: método de pesquisa para avanço da ciência e tecnologia. Porto Alegre: Bookman, 2015.

GOLDRATT, E. M.; COX, R. E. A meta. São Paulo: IMAM, 1986.

GONCCALVES, H.; GRAÇA, J. M. Conceitos bioclimáticos para os edifícios em Portugal. [s.l.] DGGE/IP-3E, 2004.

HATCHUEL, A. A foundationalist perspective for management research: a European trend and experience. Management Decision, v. 47, n. 9, p. 1458-1475, 2009.

IBGE - INSTITUTO BRASILEIRO DE GEOGRAFIA E ESTATÍSTICA. Pesquisa Nacional de saneamento básico. Rio de Janeiro: IBGE, 2008. Disponível em: <https://ww2.ibge.gov.br/home/presidencia/ noticias/imprensa/ppts/0000000105. pdf>. Acesso em 19 de abr. de 2018.

IPEA - INSTITUTO DE PESQUISA ECONÔMICA APLICADA. Pesquisa sobre pagamento por serviços ambientais urbanos para gestão de resíduos sólidos Brasília: Ipea, 2010. Disponível em: <http:// goo.gl/tTVr>. Acesso em 20 de nov. de 2018

ISWA - INTERNATIONAL SOLID WASTE ASSOCIATION. Waste and Climate Change - ISWA White Paper. USA: ISWA, 2009. Disponível em: <https://www.iswa. org/fileadmin/user_upload/_temp_/ WEB_ISWA_White_paper.pdf>. Acesso em $2 \overline{8}$ de nov. de 2017.

JONES, $O$. The grammar of ornament: illustrated by examples from various styles of ornament. New York: Dorling Kindersley Pub, 2001.

KALN/ES, S. E.; JELLE, B. P. Phase change materials and products for building applications: A state-of-the-art review and future research opportunities. Energy and Buildings, v. 94, p. 150-176, 2015.

KOLAREVIC, B.. Architecture in the digital age: design and manufacturing. Oxon: Taylor \& Francis Group, 2003, 314p.

LOOS, Adolf. Ornamento e Crime. Lisboa: Cotovia, 2006

LOVERIDGE, R.; STREHLKE, K. The Digital Ornament Using CAAD/CAAM Te- chnologies. International Journal of Architectural Computing, v. 4, n. 1, p. 33-49, 2006.

MCDONOUGH, W.; BRAUNGART, $M$. Cradle to cradle: remaking the way we make things. 1st ed. New York: North Point Press, 2002

MONTEIRO, L. M. Arquitetura da adaptação. in: SOARES, J. C.; BODE, K (Orgs.) Edifício Ambiental. São Paulo: Oficina de textos, 2015.

PICON, A. Ornament: the politics of architecture and subjectivity. Chichester, West Sussex, United Kingdom: Wiley, A John Wiley and Sons Ltd, Publication, 2013.

SALEEL, C. A.; MUJEEBU, M. A.; ALGARNI, S. Coconut oil as phase change material to maintain thermal comfort in passenger vehicles: An experimental analysis Journal of Thermal Analysis and Calorimetry, v. 136, n. 2, p. 629-636, 2019.

SAVE DE BEAURECUEIL, A.; LEE, F. Arquitetura generativa high-low: princípios e aplicações. In: GONÇALVES, J.C.S.; BODE, K. (Org.). Edifício Ambiental. São Paulo: Oficina de textos, 2015, cap. 12.

SILVA, N. F.; BRIDGES, A. H.; LIMA, E. M.; MORAIS, H. R. A.; JUNIOR, F. A. S. A indústria da construção civil está pronta para a fabricação digital e a customização em massa? Uma pesquisa sobre um caso Brasileiro. Sigradi, Sao Paulo, nov. 2009.

SIMON, Herbert A. The Sciences of the Artificial. 3ำ ed., Massachusetts: MIT Press, 1996

VAN AKEN, J. E. Management research based on the paradigm of the design sciences: the quest for field tested and grounded technological rules. Journal of Management Studies, v. 41, n. 2, p. 219 246, 2004.

VAN AKEN, J. E. Management research as a design science: articulating the research products of mode 2 knowledge production in management. British Journal of Management, v. 16, n. 1, p. 19-36, 2005.

VOLUME de resíduos urbanos crescerá de 1,3 bilhão de toneladas para 2,2 bilhões até 2025, diz PNUMA. Nações Unidas do Brasil, São Paulo, 06 de nov. de 2012. Disponível em: <https://nacoesunidas.org/ volume-de-residuos-urbanos-crescera-de-13-bilhao-de-toneladas-para-22-bilhoes-ate-2025-diz-pnuma>. Acesso em: 15 de out. de 2017 